\title{
Luminescence spectroscopy and energy level location of lanthanide ions doped in $\mathrm{La}\left(\mathrm{PO}_{3}\right)_{3}$
}

\author{
T. Shalapska ${ }^{\text {a,*, P. Dorenbos }}{ }^{\text {b }}$, A. Gektin ${ }^{\text {c }}$, G. Stryganyuk ${ }^{d}$, A. Voloshinovskii ${ }^{\text {}}$ \\ a Institute of Physics, University of Tartu, 142 Riia street, 51014 Tartu, Estonia \\ ${ }^{\mathrm{b}}$ Delft University of Technology, Faculty of Applied Sciences, Department RST/FAME, 15, Mekelweg, 2629 JB Delft, The Netherlands \\ ' Institute for Scintillation Materials, NAS Ukraine, 60 Lenin avenue, 61001 Kharkiv, Ukraine \\ ${ }^{\mathrm{d}}$ Helmholtz Centre for Environment Research, 15 Permoserstr, 04318 Leipzig, Germany \\ e Ivan Franko National University of Lviv, 8 Kyryla i Mefodiya street, 79005 Lviv, Ukraine
}

\section{A R T I C L E I N F O}

\section{Article history:}

Received 13 February 2014

Received in revised form

12 June 2014

Accepted 16 June 2014

Available online 23 June 2014

Keywords:

Lanthanide luminescence

Phosphates

Level location

Electronic structure

\begin{abstract}
A B S T R A C T
The luminescence properties of $\mathrm{Ce}^{3+}, \mathrm{Pr}^{3+}, \mathrm{Nd}^{3+}, \mathrm{Sm}^{3+}, \mathrm{Eu}^{3+}$ and $\mathrm{Tb}^{3+}$ doped $\mathrm{La}\left(\mathrm{PO}_{3}\right)_{3}$ phosphate were studied by vacuum ultra-violet spectroscopy at $10 \mathrm{~K}$ which gives information on the energies of $4 \mathrm{f}-$ $5 d$ excitation and emission and charge transfer bands of the dopants. All data are consistent with available models and have been used to construct the vacuum referred binding energy scheme for all trivalent and all divalent lanthanides in $\mathrm{La}\left(\mathrm{PO}_{3}\right)_{3}$ phosphate.
\end{abstract}

(c) 2014 Elsevier B.V. All rights reserved.

\section{Introduction}

The inorganic compounds with general formula $\operatorname{Ln}\left(\mathrm{PO}_{3}\right)_{3}(\mathrm{Ln}=\mathrm{La}$ to $\mathrm{Lu}$ and $\mathrm{Y}$ ) belong to the broader class of phosphate materials which have been extensively investigated because of a suitable absorption in the VUV region, a wide band gap together with a high chemical stability, and the relative simplicity of powder synthesis $[1,2]$. The $\mathrm{Ce}^{3+}$ luminescence in $\mathrm{Ce}\left(\mathrm{PO}_{3}\right)_{3}$ was studied by Ternane et al. [3], and in $\mathrm{Lu}\left(\mathrm{PO}_{3}\right)_{3}$ by Yuan et al. [4]. These materials are potential good phosphors, scintillators, and detectors for ionizing radiation. The scintillator properties of $\operatorname{Pr}\left(\mathrm{PO}_{3}\right)_{3}$ were studied by Jouini et al. [5]. The first investigation of $\mathrm{Nd}^{3+}$ luminescence in $\mathrm{La}\left(\mathrm{PO}_{3}\right)_{3}$ was reported by Jouini and co-authors in the framework of laser materials research [6]. The luminescence properties of $\mathrm{Eu}^{3+}$ and $\mathrm{Tb}^{3+}$ in $\mathrm{La}\left(\mathrm{PO}_{3}\right)_{3}$ and $\mathrm{Y}\left(\mathrm{PO}_{3}\right)_{3}$ as potential phosphors under VUV excitation have been discussed [2,7,8]. Much attention has been paid to the energy migration and transfer processes in Ln-based phosphate compounds [9-11].

$\mathrm{Ln}\left(\mathrm{PO}_{3}\right)_{3}(\mathrm{Ln}=\mathrm{La}$ to $\mathrm{Lu}$ and $\mathrm{Y})$ is one of the complex phosphates, which can adopt two different crystal structures depending on the ionic radius of the $\mathrm{Ln}$ ion. $\mathrm{Ln}\left(\mathrm{PO}_{3}\right)_{3}(\mathrm{Ln}=\mathrm{La}$ to $\mathrm{Gd})$ with a large radius of the Ln ion crystallizes in an orthorhombic structure with $C 222_{1}$ space group, while those with small radius of Ln ion

\footnotetext{
*Corresponding author. Tel.: +372 7374766; fax: +372 7383033 .

E-mail address: tetiana.shalapska@ut.ee (T. Shalapska).
}

( $\mathrm{Ln}=\mathrm{Gd}$ to $\mathrm{Lu}$ and $\mathrm{Y}$ ) crystallize in the monoclinic crystal structure with $\mathrm{P} 2 /$ c space group $[12,13]$. Recently, it was shown that the coordination environment of cationic sites can influence the luminescent properties of lanthanide ions in the two $\mathrm{Ln}\left(\mathrm{PO}_{3}\right)_{3}$ phosphate structures $[8,12]$. In particular, $\mathrm{La}\left(\mathrm{PO}_{3}\right)_{3}$ with the orthorhombic crystal structure has only one La-site with eight fold coordination that is available for the trivalent lanthanide ion dopant. Therefore, it is of interest to study the luminescence spectroscopy of lanthanide ions in $\mathrm{La}\left(\mathrm{PO}_{3}\right)_{3}$ and to establish where the lanthanide impurity energy levels are located. Information on the energy of electron transfer from the valence band to a trivalent lanthanide impurity forms a basis on which to construct a host referred binding energy diagram (HRBE) that presents the location of the $4 \mathrm{f}^{n}$ and $4 \mathrm{f}^{n-1} 5 \mathrm{~d}$ levels of all divalent and trivalent lanthanide ions relative to the top of the valence band [14,15]. Recently the chemical shift model was proposed that allows to convert a HRBE scheme into a vacuum referred binding energy scheme (VRBE) where all level energies are relative to that of an electron at rest in vacuum [16,17]. Such scheme provides a new method for the visualization of the location of the relevant lanthanide states with respect to each other and to the bands of the host compound. The first VRBE schemes were constructed for fluorides, aluminates, nitride compounds [18] and also already presented for some oxide materials [19-21].

In this work we present studies of the luminescence spectroscopy of lanthanides in $\mathrm{La}\left(\mathrm{PO}_{3}\right)_{3}$ under vacuum ultra-violet excitation. Data are used to construct the electronic structure scheme 
with the binding energy of the electrons in the lanthanide impurity states and host band states. The spectroscopic information and the level scheme of $\mathrm{La}\left(\mathrm{PO}_{3}\right)_{3}: \mathrm{Ln}$ compound may then form a benchmark for the entire family of $\operatorname{Ln}\left(\mathrm{PO}_{3}\right)_{3}$ compounds ( $\mathrm{Ln}=\mathrm{La}$ to $\mathrm{Gd}$ ). Additionally, we will compare the spectroscopy and the energy level scheme of $\mathrm{La}\left(\mathrm{PO}_{3}\right)_{3}$ : $\mathrm{Ln}$ with the previousstudied system $\mathrm{LiYP}_{4} \mathrm{O}_{12}: \mathrm{Ln}[22]$ and other phosphate compounds.

\section{Experimental details}

The studies in this work were performed on powder samples of $\mathrm{La}\left(\mathrm{PO}_{3}\right)_{3}: 5$ at\% $\mathrm{Ln}(\mathrm{Ln}=\mathrm{Ce}, \mathrm{Pr}, \mathrm{Nd}, \mathrm{Sm}, \mathrm{Eu}$ and $\mathrm{Tb})$ metaphosphate compounds prepared using the melt solution technique. For the synthesis of the phosphate, $\mathrm{La}_{2} \mathrm{O}_{3}, \mathrm{CeO}_{2}, \mathrm{Pr}_{2} \mathrm{O}_{3}, \mathrm{Nd}_{2} \mathrm{O}_{3}, \mathrm{Sm}_{2} \mathrm{O}_{3}$, $\mathrm{Eu}_{2} \mathrm{O}_{3}$ and $\mathrm{Tb}_{2} \mathrm{O}_{3}$ oxide compounds together with $\mathrm{NH}_{4} \mathrm{H}_{2} \mathrm{PO}_{4}$ were used as the starting materials. They were mixed and fired in quarts crucibles first at $300{ }^{\circ} \mathrm{C}$ for $24 \mathrm{~h}$ and then at $800{ }^{\circ} \mathrm{C}$ for $12 \mathrm{~h}$. After cooling down to RT, the samples were washed and drained.

Measurements of luminescence excitation and emission spectra, decay kinetics within a 100 ns time-gate at $10 \mathrm{~K}$, were performed at Deutsches Elektronen Synchotron (DESY, Hamburg) using synchrotron radiation from the DORIS III storage ring employing the SUPERLUMI experimental facility of HASYLAB [23]. A helium flowtype cryostat was used to stabilize the temperature at $T=10 \mathrm{~K}$. The emission in the UV visible range was recorded with a spectral resolution of $0.3-5.0 \mathrm{~nm}$ using a $0.3 \mathrm{~m}$ ARC Spectra Pro 308 monochromator-spectrograph in Czerny-Turner mounting equipped with 1200 or 300 groves/mm gratings and a Princeton Instruments CCD detector $(1100 \times 300$ pixels $)$ or a HAMAMATSU R6358P photomultiplier. The VUV emission spectra were recorded with $2 \mathrm{~nm}$ resolution using a $0.5 \mathrm{~m}$ Pouey-type monochromator equipped with a solar blind Hamamatsu R6836 photomultiplier. Luminescence excitation spectra were scanned within the $3.7-10 \mathrm{eV}$ range with the resolution of $0.32 \mathrm{~nm}$ using the primary $2 \mathrm{~m}$ monochromator in 151 McPherson mounting (equipped with a Jobin Yvon holographic concave grating with $\mathrm{Al}+\mathrm{MgF}_{2}$ coating and 1200 groves $/ \mathrm{mm}$ ). The primary monochromator was calibrated with $0.005 \mathrm{~nm}$ accuracy using the ${ }^{1} \mathrm{~S}_{0} \rightarrow{ }^{3} \mathrm{P}_{j}$ absorption of atomic xenon and krypton gases as a reference. Luminescence excitation spectra were corrected for the incident photon flux by using Na-salycilate as a reference.

\section{Experimental results}

\section{1. $C e^{3+}$ doping}

The low temperature emission and excitation spectra of the $\mathrm{La}\left(\mathrm{PO}_{3}\right)_{3}: \mathrm{Ce}^{3+}$ metaphosphate are shown in Fig. 1. The emission spectra of the $\mathrm{La}\left(\mathrm{PO}_{3}\right)_{3}: \mathrm{Ce}^{3+}$ consist of the UV-emission bands peaking at 4.09 and $3.85 \mathrm{eV}$ which are ascribed to the transitions from the lowest $\mathrm{Ce}^{3+} 5 \mathrm{~d}$ excited state to the $4 \mathrm{f}$ ground state levels ${ }^{2} \mathrm{~F}_{5 / 2}$ and ${ }^{2} \mathrm{~F}_{7 / 2}$. The energy gap between the maxima coincides with the spin-orbit splitting of the $\mathrm{Ce}^{3+}$ ground state. The excitation spectrum of $\mathrm{La}\left(\mathrm{PO}_{3}\right)_{3}: \mathrm{Ce}^{3+}$ measured for the $\mathrm{Ce}^{3+}$-related $\left(5 \mathrm{~d}_{1}-{ }^{2} \mathrm{~F}_{7 / 2}\right)$ emission band $\left(E_{\mathrm{em}}=3.82 \mathrm{eV}\right)$ reveals the presence of a structure typical for a $\mathrm{Ce}^{3+}$ ion in a low-symmetry crystal field with a dodecahedral coordination around the $\mathrm{Ce}^{3+}$ ion. Five excitation bands with the maxima at 4.27, $4.635 .44,6.11$ and $6.43 \mathrm{eV}$ are attributed to the transitions from the $4 \mathrm{f}$ ground state to the $5 \mathrm{~d}$ excited states of a $\mathrm{Ce}^{3+}$ ion, which are split in the crystal field of the $\mathrm{La}\left(\mathrm{PO}_{3}\right)_{3}$ host lattice into $5 \mathrm{~d}_{1} \ldots 5 \mathrm{~d}_{5}$ levels.

The values of the crystal field splitting, i.e., the energy difference between the highest-energy and the lowest-energy $5 \mathrm{~d}$ bands $\left(\varepsilon_{\mathrm{cfs}}=2.16 \mathrm{eV}\right)$ and the centroid shift, i.e., the average energy of the five $5 \mathrm{~d}$ bands $\left(\varepsilon_{\mathrm{c}}=0.974 \mathrm{eV}\right)$, are in a good agreement with expectation [24]. The peak due to the phosphate group excitations at $8.45 \mathrm{eV}$ is weak, which indicates that the transfer efficiency of the excitation energy to $\mathrm{Ce}^{3+}$ is a rather poor. The decay time of $\mathrm{Ce}^{3+}$ emission upon the excitation in the region of the $\mathrm{Ce}^{3+} 4 \mathrm{f}-$ $5 \mathrm{~d}^{1}$ excitation is exponential and can be characterized by the decay time of 14.8 ns (see inset Fig. 1).

\section{2. $\mathrm{Pr}^{3+}$ doping}

Fig. 2 presents the excitation and emission spectra of $\mathrm{Pr}^{3+}$ in $\mathrm{La}\left(\mathrm{PO}_{3}\right)_{3}$. The emission spectrum of $\mathrm{La}\left(\mathrm{PO}_{3}\right)_{3}: \mathrm{Pr}^{3+}$ reveals emission bands in the $6-2.8 \mathrm{eV}$ spectral range typical for the $5 \mathrm{~d} 4 \mathrm{f}^{1} \rightarrow 4 \mathrm{f}^{2}$ intracenter transitions in the $\mathrm{Pr}^{3+}$ ion. It is well established that the energy of the main $4 \mathrm{f}-5 \mathrm{~d}$ excitation bands for $\mathrm{Pr}^{3+}$ can be predicted from the corresponding energies observed for $\mathrm{Ce}^{3+}$ by adding $1.56 \mathrm{eV} \pm 0.09 \mathrm{eV}$ energy [15]. In Fig. 2, we therefore also presented the $\mathrm{Ce}^{3+}$ excitation spectrum from Fig. 1 shifted to $1.57 \mathrm{eV}$ higher energy. A value of $1.57 \mathrm{eV}$ provides a good agreement with the Pr excitation bands. One may recognize the $5 \mathrm{~d}_{1-5}$ excitation bands of $\mathrm{Ce}^{3+}$ within the excitation spectrum for $\mathrm{Pr}^{3+}$ emission. The main $\mathrm{Pr}^{3+}$ excitation bands are accompanied by satellite bands at higher energy. For example the $5 d_{1}$ and $5 d_{2} \operatorname{Pr}^{3+}$ excitation bands at 5.84 and $6.22 \mathrm{eV}$ are accompanied by excitation bands at 6.03, 6.29, and $6.46 \mathrm{eV}$. These satellite bands are attributed to the coupling between the electron in the $5 \mathrm{~d}$ orbital with the electron remaining in the $4 \mathrm{f}$ orbital. Similar structure of the excitation spectra of $\mathrm{Pr}^{3+}$ emission was observed for

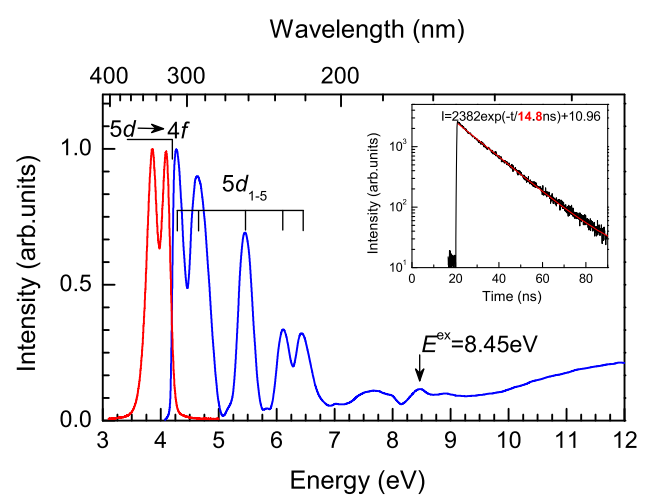

Fig. 1. The excitation spectrum of the $3.82 \mathrm{eV}$ emission and the emission spectrum under the $5.46 \mathrm{eV}$ excitation of $\mathrm{Ce}^{3+}$ in $\mathrm{La}\left(\mathrm{PO}_{3}\right)_{3}$ metaphosphate at $10 \mathrm{~K}$. In the inset the low temperature decay curve of the $\mathrm{Ce}^{3+}$ luminescence for $\mathrm{La}\left(\mathrm{PO}_{3}\right)_{3}: \mathrm{Ce}^{3+}$ upon the excitation in the region of the $\mathrm{Ce}^{3+} 4 \mathrm{f}-5 \mathrm{~d}_{1}$ absorption $\left(E_{\mathrm{exc}}=4.27 \mathrm{eV}\right.$ and $E_{\mathrm{em}}=3.82 \mathrm{eV}$ ) is presented.

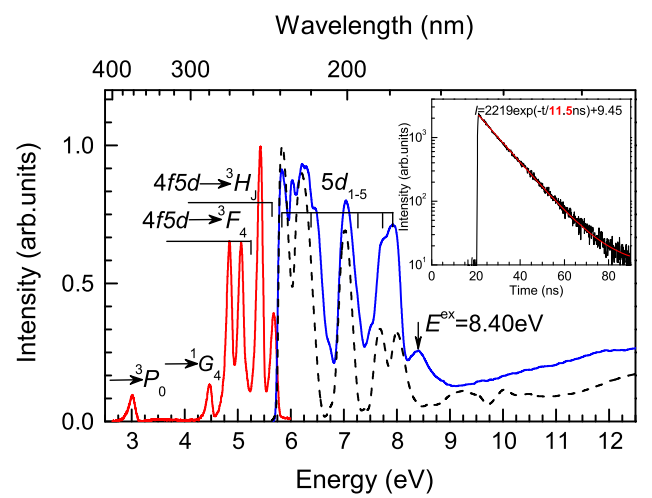

Fig. 2. The excitation spectrum of $5.39 \mathrm{eV}$ emission and the emission spectrum under $7.04 \mathrm{eV}$ excitation of $\mathrm{Pr}^{3+}$ in $\mathrm{La}\left(\mathrm{PO}_{3}\right)_{3}$ at $T=10 \mathrm{~K}$. The dashed curve shows the excitation spectrum of the $\mathrm{Ce}^{3+}$ emission shifted with $1.57 \mathrm{eV}$ to higher energy. In the inset the decay curve of the $\mathrm{Pr}^{3+}$ luminescence for $\mathrm{La}\left(\mathrm{PO}_{3}\right)_{3}: \mathrm{Pr}^{3+}$ upon the excitation in the region of the $\mathrm{Pr}^{3+} 4 \mathrm{f}-5 \mathrm{~d}$ absorption is presented at $T=10 \mathrm{~K}$. 
$\mathrm{YPO}_{4}: \mathrm{Pr}^{3+}$ [25] and $\mathrm{LiYP}_{4} \mathrm{O}_{12}: \mathrm{Pr}^{3+}$ [22]. The excitation bands peaking at 7.04, 7.7 and $7.92 \mathrm{eV}$ correspond to the $5 \mathrm{~d}_{3} 5 \mathrm{~d}_{4}$ and $5 d_{5}$ related excitation bands. The emission bands at 5.67, 5.43, $5.07,4.84$, and $4.47 \mathrm{eV}$ are identified as emissions from the lowest 4f5d state to ${ }^{3} \mathrm{H}_{4},{ }^{3} \mathrm{H}_{5},{ }^{3} \mathrm{H}_{6},{ }^{3} \mathrm{~F}_{2},{ }^{3} \mathrm{~F}_{3,4}$, and ${ }^{1} \mathrm{G}_{4}$ states of $\mathrm{Pr}^{3+}$, respectively. The emission band at $3.0 \mathrm{eV}$ can be the spin allowed transition to the ${ }^{3} \mathrm{P}_{0}$ level. The Stokes shift between the $5 \mathrm{~d}_{1}$ excitation and emission bands of $\mathrm{La}\left(\mathrm{PO}_{3}\right)_{3}: \mathrm{Pr}^{3+}$ is $0.17 \mathrm{eV}$. The maximum of the phosphate group excitation $E^{\mathrm{ex}}$ is $8.40 \mathrm{eV}$ which is close to that observed for $\mathrm{La}\left(\mathrm{PO}_{3}\right)_{3}: \mathrm{Ce}^{3+}$.

The decay curve of the $\mathrm{Pr}^{3+} 5 \mathrm{~d}-4 \mathrm{f}$ luminescence in $\mathrm{La}\left(\mathrm{PO}_{3}\right)_{3}$ excited at $6.32 \mathrm{eV}$ demonstrates a single-exponential behavior with the decay time $\tau=11.5 \mathrm{~ns}$ at $T=10 \mathrm{~K}$, which is similar to the $\mathrm{Pr}^{3+} 5 \mathrm{~d}-4 \mathrm{f}$ emission decay observed in other Pr-doped phosphates (11.8 ns for $\mathrm{YPO}_{4}$ and $15.4 \mathrm{~ns}$ for $\mathrm{LuPO}_{4}, 13.4 \mathrm{~ns}$ for $\mathrm{LaPO}_{4}$ : $\mathrm{Pr}^{3+}$ [26], and $10.5 \mathrm{~ns}$ for $\mathrm{LiYP}_{4} \mathrm{O}_{12}: \mathrm{Pr}^{3+}$ [27]). The life time of the $\mathrm{Pr}^{3+}$ emission is a factor 1.3 shorter than that observed for $\mathrm{Ce}^{3+}$. Usually, the photon cascade emission process in $\operatorname{Pr}^{3+}$-activated compounds is only realized when the lowest crystal field split level of the $\mathrm{Pr}^{3+} 4 \mathrm{f}^{1} 5 \mathrm{~d}^{1}$ configuration is located energetically above the ${ }^{1} \mathrm{~S}_{0}$ state of the $4 \mathrm{f}^{2}$ configuration [28]. For $\mathrm{Pr}^{3+}$-doped $\mathrm{La}\left(\mathrm{PO}_{3}\right)_{3}$ the relaxed lowest energy $4 \mathrm{f}-5 \mathrm{~d}$ state is located below the $4 \mathrm{f}^{2}\left[{ }^{1} \mathrm{~S}_{0}\right]$ state, and photon cascade emission from the $4 \mathrm{f}^{2}\left[{ }^{1} \mathrm{~S}_{0}\right]$ therefore does not occur.

\section{3. $N d^{3+}$ doping}

Fig. 3 presents the excitation and emission spectra for $\mathrm{Nd}^{3+}$ in $\mathrm{La}\left(\mathrm{PO}_{3}\right)_{3}$. The lowest $5 \mathrm{~d}$ state of $\mathrm{Nd}^{3+}$ is predicted at about $2.80 \mathrm{eV}$ higher energy than that for $\mathrm{Ce}^{3+}$ [15]. In Fig. 3 the first four excitation bands observed for $\mathrm{Ce}^{3+}$ are shifted by $2.75 \mathrm{eV}$ in energy in order to compare with the $\mathrm{Nd}^{3+}$ excitation bands. The bands in the $\mathrm{Nd}^{3+}$ excitation spectrum at 7.0 and $7.41 \mathrm{eV}$ can be identified as the transition to the lowest energy $5 d_{1}$ and $5 d_{2}$ states. The emission to the $4 \mathrm{f}^{3}\left[{ }^{4} \mathrm{I}_{9 / 2}\right]$ ground state is observed as a clear band at $6.87 \mathrm{eV}$ yielding a Stokes shift of $0.13 \mathrm{eV}$. The emission to the $4 \mathrm{f}^{3}\left[{ }^{4} \mathrm{I}_{11 / 2}\right]$ state is seen as a clear band at $6.65 \mathrm{eV}$. The emission to the ${ }^{4} \mathrm{I}_{13 / 2}$ and ${ }^{4} \mathrm{I}_{15 / 2}$ states is too weak to be observed. The emission bands around $5.46 \mathrm{eV}$ and $4.74 \mathrm{eV}$ are due to transitions to higher energy $4 \mathrm{f}^{3}$ states. The decay time of $\mathrm{Nd}^{3+} 5 \mathrm{~d}-4 \mathrm{f}$ luminescence is $5.8 \mathrm{~ns}$ as shown in the inset of Fig. 3.

\section{4. $\mathrm{Sm}^{3+}$ doping}

The excitation and emission spectra of $\mathrm{Sm}^{3+}$-doped $\mathrm{La}\left(\mathrm{PO}_{3}\right)_{3}$ are shown in Fig. 4. The sharp emission lines at 2.212, 2.083 and $1.933 \mathrm{eV}$ are due to the $4 \mathrm{f}^{5} \rightarrow 4 \mathrm{f}^{5}$ transitions starting from the ${ }^{4} \mathrm{G}_{5 / 2}$

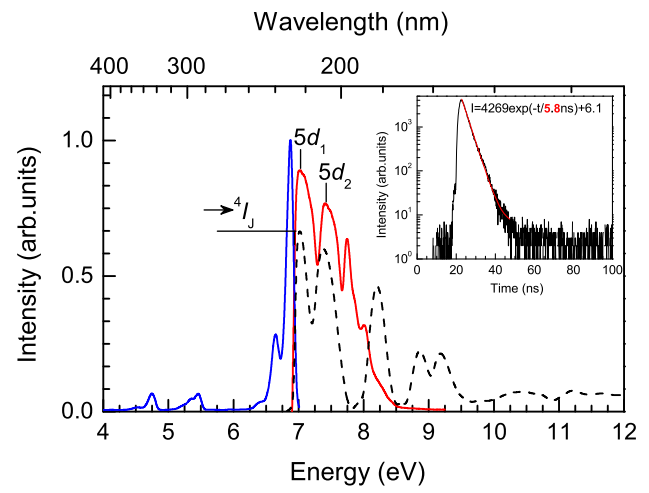

Fig. 3. The excitation spectrum of $6.84 \mathrm{eV}$ emission and the emission spectrum under $7.12 \mathrm{eV}$ excitation of $\mathrm{Nd}^{3+}$ in $\mathrm{La}\left(\mathrm{PO}_{3}\right)_{3}$ at $10 \mathrm{~K}$. The dashed curve is part of the excitation spectrum of the $\mathrm{Ce}^{3+}$ emission shifted by $2.75 \mathrm{eV}$ to higher energy. The inset presents the low temperature decay kinetics curve of $\mathrm{Nd}^{3+}$ luminescence in $\mathrm{La}\left(\mathrm{PO}_{3}\right)_{3}$ upon excitation at $E_{\text {exc }}=6.81 \mathrm{eV}$. to the ${ }^{6} \mathrm{H}_{5 / 2}$ ground state and higher ${ }^{6} \mathrm{H}_{7 / 2}$, and ${ }^{6} \mathrm{H}_{9 / 2}$ states, respectively. Usually, the first $4 \mathrm{f}^{5}-4 \mathrm{f}^{4} 5 \mathrm{~d}$ excitation band of $\mathrm{Sm}^{3+}$ is at $3.22 \mathrm{eV}$ higher energy than that for $\mathrm{Ce}^{3+}$ and it is then predicted at $7.49 \mathrm{eV}$. Therefore, the band at $7.46 \mathrm{eV}$ is assigned to that excitation. The relatively narrow $4 \mathrm{f}-5 \mathrm{~d}$ excitation bands are located on top of a much broader excitation band that we assign to the charge transfer $(C T)$ band. The maximum of this $C T$-band is around $7.13 \mathrm{eV}$. The $4 \mathrm{f}-5 \mathrm{~d}$ excitation features on a top of the broad underlying $C T$-band are very similar as in $\mathrm{LiYP}_{4} \mathrm{O}_{12}: \mathrm{Sm}^{3+}$. According to data presented in Ref. [11], the decay time of $\mathrm{Sm}^{3+}$ luminescence $\left({ }^{4} \mathrm{G}_{5 / 2} \rightarrow{ }^{6} \mathrm{H}_{9 / 2}\right)$ in $\mathrm{La}\left(\mathrm{PO}_{3}\right)_{3}$ phosphate under excitation in the region of the ${ }^{4} \mathrm{I}_{J}$ level is exponential with a decay time $2.6 \mathrm{~ms}$ at $300 \mathrm{~K}$.

\section{5. $\mathrm{Eu}^{3+}$ doping}

Fig. 5 presents the excitation and emission spectra for $\mathrm{Eu}^{3+}$ in $\mathrm{La}\left(\mathrm{PO}_{3}\right)_{3}$. 5d-4f emission has never been observed with $\mathrm{Eu}^{3+}$ in any compound, and the emission spectrum shows only narrow intense $4 \mathrm{f}^{6}-4 \mathrm{f}^{6} \mathrm{emission}$ lines at 1.783, 1.9 (weak), 2.014, 2.084, 2.099 and $2.117 \mathrm{eV}$ due to the ${ }^{5} \mathrm{D}_{0} \rightarrow{ }^{7} \mathrm{~F}_{J}(J=1,2,3$ and 4$)$ radiative transitions. The excitation band to the lowest energy $4 \mathrm{f}^{5} 5 \mathrm{~d}$ state is expected at $4.38 \mathrm{eV}$ higher than that for $\mathrm{Ce}^{3+}$ yielding a predicted value of $8.65 \mathrm{eV}$ which is the region of the phosphate group excitation band seen at $E^{\mathrm{ex}}=8.50 \mathrm{eV}$. The strong and broad excitation starting at $5.80 \mathrm{eV}$ is like for $\mathrm{Sm}^{3+}$ attributed to the $C T$-band, i.e., an electron is excited from the top of the valence band to $\mathrm{Eu}^{3+}$. The maximum of the $C T$-band is at $5.84 \mathrm{eV}$. In addition, weak narrow excitation lines at 4.16 and $3.87 \mathrm{eV}$ are

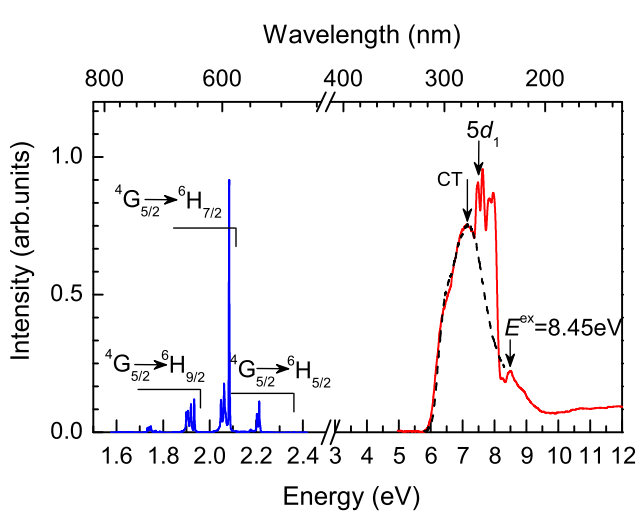

Fig. 4. The excitation spectrum of $2.07 \mathrm{eV}$ emission and the emission spectrum under $7.13 \mathrm{eV}$ excitation of $\mathrm{Sm}^{3+}$ in $\mathrm{La}\left(\mathrm{PO}_{3}\right)_{3}$ at $10 \mathrm{~K}$. The dashed curve is part of the excitation spectrum of the $\mathrm{Eu}^{3+}$ emission shifted by $1.30 \mathrm{eV}$ to higher energy.

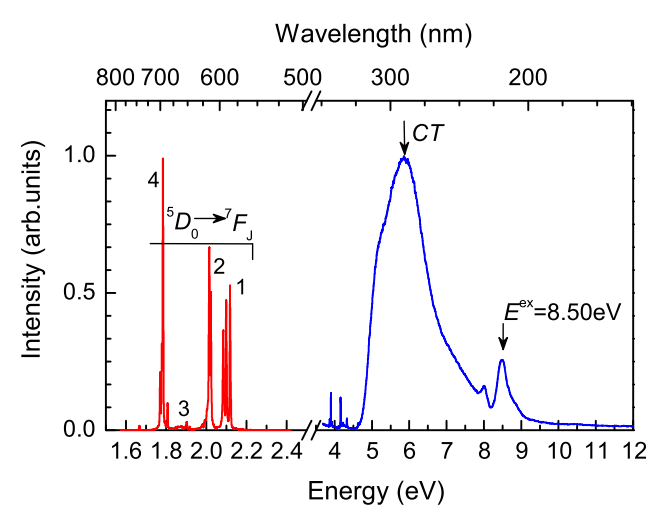

Fig. 5. The excitation spectrum of $2.11 \mathrm{eV}$ emission and the emission spectrum under $7.09 \mathrm{eV}$ excitation of $\mathrm{Eu}^{3+}$ in $\mathrm{La}\left(\mathrm{PO}_{3}\right)_{3}$ at $10 \mathrm{~K}$. 
observed that correspond to the ${ }^{7} \mathrm{~F}_{0} \rightarrow{ }^{5} \mathrm{~F}_{J}$ and ${ }^{7} \mathrm{~F}_{0} \rightarrow{ }^{5} \mathrm{H}_{J}$ transitions of $\mathrm{Eu}^{3+}$.

When the energy of $C T$ to $\mathrm{Eu}^{3+}$ is known the energy of $C T$ to any other trivalent lanthanide in the same compound can be predicted. That for $\mathrm{Sm}^{3+}$ is always at $1.25 \mathrm{eV}$ higher energy than that for $\mathrm{Eu}^{3+}$. To demonstrate this, the excitation spectra for $\mathrm{Eu}^{3+}$ have been shifted by $1.3 \mathrm{eV}$ and shown in Fig. 4. It provides a prediction of the contribution from the $\mathrm{Sm}^{3+} C T$-band to the excitation spectrum. The decay kinetics of the $\mathrm{Eu}^{3+}{ }^{5} \mathrm{D}_{0} \rightarrow{ }^{7} \mathrm{~F}_{2}$ luminescence in $\mathrm{La}\left(\mathrm{PO}_{3}\right)_{3}$ were studied by Ternane et al. [3] and determined to be $3.85 \mathrm{~ms}$ at $300 \mathrm{~K}$ and $4.30 \mathrm{~ms}$ at $77 \mathrm{~K}$.

\section{6. $T b^{3+}$ doping}

Fig. 6(a) shows the excitation and emission spectra of $\mathrm{La}\left(\mathrm{PO}_{3}\right)_{3}$ : $\mathrm{Tb}^{3+}$. In the emission spectra typical narrow emission lines are seen that correspond to the emissions from the $4 \mathrm{f}^{8}\left[{ }^{5} \mathrm{D}_{3}\right]$ and $4 \mathrm{f}^{8}\left[{ }^{5} \mathrm{D}_{4}\right]$ states to the lower energy ${ }^{7} \mathrm{~F}_{J}$ multiples. The spin allowed transitions starting from the so-called low spin [LS] $5 d_{1}$ state of $\mathrm{Tb}^{3+}$ are always found at $1.6 \mathrm{eV}$ higher energy than those from the $5 d_{1}$ state of $\mathrm{Ce}^{3+}$ [29]. In the case of $\mathrm{La}\left(\mathrm{PO}_{3}\right)_{3}: \mathrm{Tb}^{3+}$ the [LS] $5 \mathrm{~d}_{1}$ excitation band is predicted at $5.93 \mathrm{eV}$ which is in a good agreement with Fig. 6(a). The weak excitation band at $1.01 \mathrm{eV}$ lower energy, $4.92 \mathrm{eV}$, is attributed to the first spin forbidden transitions to the high spin [HS] $5 \mathrm{~d}_{1}$ state. The dashed line in Fig. 6 (b) shows the excitation spectrum of $\mathrm{Ce}^{3+}$, which is shifted in energy by $1.64 \mathrm{eV}$. The location of the first four shifted $\mathrm{Ce}^{3+}$ excitation bands then agrees well with the observed bands of $\mathrm{Tb}^{3+}$. The fifth excitation band of $\mathrm{Tb}^{3+}$ appearing as a shoulder band at $7.89 \mathrm{eV}$ is at $0.16 \mathrm{eV}$ lower energy than that predicted from the $\mathrm{Ce}^{3+}$ excitation spectrum. This suggests that the total crystal field splitting for $\mathrm{Tb}^{3+}$ is $0.16 \mathrm{eV}$ smaller than that observed for $\mathrm{Ce}^{3+}$ and $\mathrm{Pr}^{3+}$ ions in this host lattice. The spin forbidden transition to $[\mathrm{HS}] 5 \mathrm{~d}_{3}$ is predicted to coincide with the transition to the
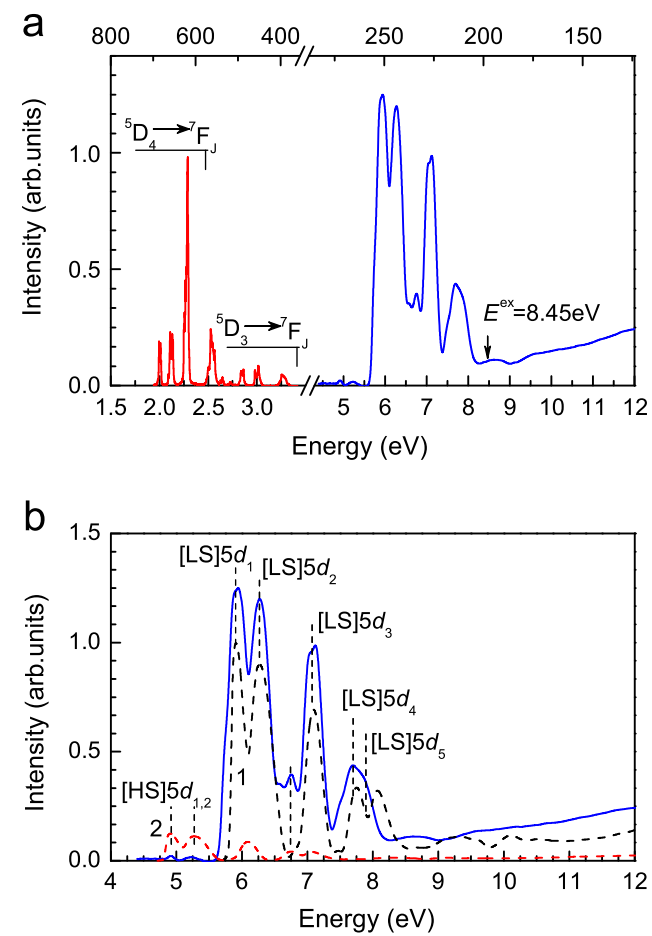

Fig. 6. (a) The excitation spectrum of $2.27 \mathrm{eV}$ emission and the emission spectrum under $6.89 \mathrm{eV}$ excitation of $\mathrm{Tb}^{3+}$ in $\mathrm{La}\left(\mathrm{PO}_{3}\right)_{3}$ at $10 \mathrm{~K}$. (b) The excitation spectrum of $2.27 \mathrm{eV}$ emission of $\mathrm{Tb}^{3+}$ together with the dashed curves (1) and (2) which are relevant parts of the excitation spectrum of $\mathrm{Ce}^{3+}$ emission shifted with 1.64 and $0.64 \mathrm{eV}$ to higher energy, respectively.
[LS] $5 d_{2}$. To illustrate this, the excitation spectrum of $\mathrm{Ce}^{3+}$ is shifted by $0.64 \mathrm{eV}$ and shown as dashed curve 2 in Fig. 6(b). The excitation bands for $\mathrm{Ce}^{3+}$ then approximately reproduce the energies for the weak spin forbidden transitions to the [HS] $5 \mathrm{~d}_{i}$ states of $\mathrm{Tb}^{3+}$. Those to $5 \mathrm{~d}_{1}, 5 \mathrm{~d}_{2}$, and $5 \mathrm{~d}_{4}$ can then be identified. The decay kinetics of the ${ }^{5} \mathrm{D}_{4} \rightarrow{ }^{7} \mathrm{~F}_{5}$ transition of $\mathrm{Tb}^{3+}$ in $\mathrm{La}\left(\mathrm{PO}_{3}\right)_{3}$ under excitation in the region of the [LS] $5 \mathrm{~d}_{3}$ absorption was studied by Wang et al. [2] and found to be about $4.47 \mathrm{~ms}$ at $300 \mathrm{~K}$.

\section{Discussion}

Using the four crucial parameters as the redshift, the centroid shift, CT-energies, and exciton creation energies (see Table 1), the host referred binding energy (HRBE) and the vacuum referred binding energy (VRBE) scheme are constructed for $\mathrm{La}\left(\mathrm{PO}_{3}\right)_{3}: \mathrm{Ln}$ and presented in Fig. 7. The energy difference $E_{\mathrm{VC}}$ between the top of the valence band at $E_{\mathrm{V}}$ and the bottom of the conduction band at $E_{\mathrm{C}}$ is taken $8 \%$ larger than the exciton creation energy $E^{\mathrm{ex}}=8.45 \mathrm{eV}$ in order to account for the estimated exciton binding energy [18]. $E^{C T}$ defines the energy difference between $E_{\mathrm{V}}$ and the ground state energy $E_{4 \mathrm{f}}(7,2+, \mathrm{A})$ of $\mathrm{Eu}^{2+}$. The ground state energy of $\mathrm{Eu}^{3+}$ is at $U(6, A)$ lower energy. $U(6, A)$ is known as the 4 f-electron Coulomb repulsion energy and can be estimated from the centroid shift as in Ref. [30] where data for different inorganic compounds were presented. A value of $7.26 \mathrm{eV}$ pertains to $\mathrm{La}\left(\mathrm{PO}_{3}\right)_{3}$ and then with the chemical shift model the absolute VRBE of the $4 \mathrm{f}$ ground state

Table 1

The experimental compound dependent input data for the shift model and the energies calculated therefrom; all energies are in $\mathrm{eV}$.

\begin{tabular}{lcc}
\hline & $\mathrm{La}\left(\mathrm{PO}_{3}\right)_{3}$ & $\mathrm{LiYP}_{4} \mathrm{O}_{12}$ \\
\hline Exp. input & & \\
$E^{\text {ex }}(\mathrm{A})$ & 8.45 & 8.63 \\
$D(3+, \mathrm{A})$ & 1.85 & 1.93 \\
$\varepsilon_{\mathrm{c}}(1,3+, \mathrm{A})$ & 0.974 & 0.972 \\
$E^{\text {exch }}(8,3+, \mathrm{A})$ & 1.02 & 0.97 \\
$E^{C T}(6,3+, \mathrm{A})$ & 5.84 & 6.15 \\
Model ouput & & \\
$D(2+, \mathrm{A})$ & 0.95 & 1.0 \\
$U(6, \mathrm{~A})$ & 7.25 & 7.26 \\
$E_{4 \mathrm{f}}(7,2+, \mathrm{A})$ & -4.20 & -4.20 \\
$E_{5 \mathrm{~d}}(7,2+, \mathrm{A})$ & -0.88 & -0.85 \\
$E_{4 \mathrm{f}}(1,3+, \mathrm{A})$ & -6.21 & -6.23 \\
$E_{5 \mathrm{~d}}(1,3+, \mathrm{A})$ & -1.94 & -2.04 \\
$E_{\mathrm{V}}(\mathrm{A})$ & -9.99 & -10.4 \\
$E_{\mathrm{X}}(\mathrm{A})$ & -1.59 & -1.72 \\
$E_{\mathrm{C}}(\mathrm{A})$ & -0.86 & -1.03 \\
\hline
\end{tabular}

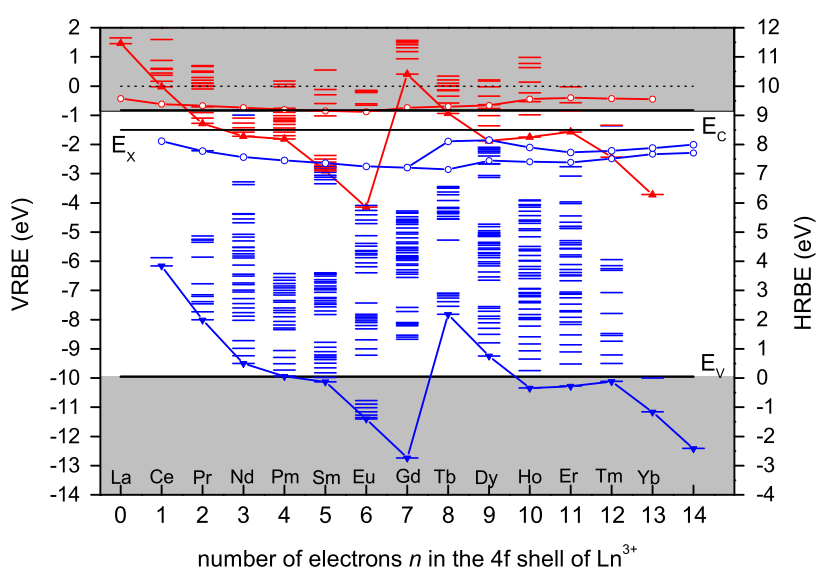

Fig. 7. The HRBE and VRBE scheme for the divalent and trivalent lanthanides in $\mathrm{La}\left(\mathrm{PO}_{3}\right)_{3}$. 
Table 2

Observed and predicted energies for the first $4 \mathrm{f}-5 \mathrm{~d}$ transition $E_{\mathrm{fd}}$ and for the $C T$-band energy $E^{C T}$. Values within brackets are for the first spin allowed $4 \mathrm{f}-5 \mathrm{~d}$ transition; all energies are in $\mathrm{eV}$.

\begin{tabular}{llllll}
\hline $\mathrm{Ln}^{3+} n$ & $\begin{array}{l}E_{\mathrm{df}} \mathrm{La}\left(\mathrm{PO}_{3}\right)_{3} \\
\text { obs. }\end{array}$ & $\begin{array}{l}E_{\mathrm{df}} \mathrm{La}\left(\mathrm{PO}_{3}\right)_{3} \\
\text { pred. }\end{array}$ & $\begin{array}{l}E_{\mathrm{CT}} \mathrm{La}\left(\mathrm{PO}_{3}\right)_{3} \\
\text { obs. }\end{array}$ & $\begin{array}{l}E_{\mathrm{CT}} \mathrm{La}\left(\mathrm{PO}_{3}\right)_{3} \\
\text { pred. }\end{array}$ \\
\hline $\mathrm{Ce}$ & 1 & 4.27 & 4.27 & & 9.87 \\
$\mathrm{Pr}$ & 2 & 5.84 & 5.78 & & 8.63 \\
$\mathrm{Nd}$ & 3 & 7.0 & 7.07 & & 8.30 \\
$\mathrm{Pm}$ & 4 & - & 7.39 & 7.13 & 8.12 \\
$\mathrm{Sm}$ & 5 & 7.46 & 7.49 & 5.84 & 7.04 \\
$\mathrm{Eu}$ & 6 & - & 8.65 & & 5.80 \\
$\mathrm{Gd}$ & $7-$ & 9.95 & & 10.47 \\
$\mathrm{~Tb}$ & 8 & $4.92(5.93)$ & 5.05 & & 9.03 \\
$\mathrm{Dy}$ & $9-$ & 6.75 & 7.80 & 8.10 \\
$\mathrm{Ho}$ & $10-$ & 7.70 & & 8.24 \\
$\mathrm{Er}$ & $11-$ & 7.65 & & 7.57 \\
$\mathrm{Tm}$ & 12 & - & 8.85 & 6.29 \\
$\mathrm{Yb}$ & $13-$ & & & \\
\hline
\end{tabular}

energies for $\mathrm{Eu}^{2+}$ and $\mathrm{Eu}^{3+}$ are obtained which defines the left hand VRBE scale in Fig. 7.

The binding energies for divalent lanthanides other than $\mathrm{Eu}^{2+}$ are placed by using the $\Delta E(n+1,7,2+)$ parameters which give the characteristics upper double zigzag binding energy curve. $\Delta E(n, 6,3+)$ parameters provide the lower double zigzag curve for the trivalent lanthanides: to this zigzag curve one may add the energy of the first spin allowed $4 \mathrm{f}-5 \mathrm{~d}$ transitions by employing $E_{\mathrm{fd}}(n, Q, \mathrm{~A})=E_{\mathrm{fd}}(n, Q$,free $)-D(Q, \mathrm{~A})$. The first high spin [HS] 5d-level can be placed by multiplying $E^{\text {exch }}(n, 3+$,fluoride) values by $1.02 \mathrm{eV}$ being the ratio $E^{\operatorname{exch}}\left(n, 3+, \mathrm{La}\left(\mathrm{PO}_{3}\right)_{3}\right) / E^{\text {exch }}(n, 3+$,fluoride $)$ and subtracting that exchange splitting energy from the energy of the [LS] level. For indicating and determining the high spin [HS] 5d-states energies in $\mathrm{La}\left(\mathrm{PO}_{3}\right)_{3}$ we used the standardized notation and method from Ref. [30]. The VRBE scheme of $\mathrm{La}\left(\mathrm{PO}_{3}\right)_{3}: \mathrm{Ln}$ provides the information about the location of the lanthanide states and the host band states of $\mathrm{La}\left(\mathrm{PO}_{3}\right)_{3}$. In column 4 of Table 2 we compiled those predicted values using the most recent data from Ref. [30]. In column 3 the observed energies of $4 \mathrm{f}-5 \mathrm{~d}$ transitions of Ln ions in $\mathrm{La}\left(\mathrm{PO}_{3}\right)_{3}$ are presented and the agreement with predicted energies is evident. The first spin-allowed transition was studied only for $\mathrm{Tb}^{3+}$ ion (shown within brackets). The CT-band energies of all lanthanides in $\mathrm{La}\left(\mathrm{PO}_{3}\right)_{3}: \mathrm{Ln}$ are also predicted and compiled in column 6 of Table 2. The energy of the observed CT-band for $\mathrm{Sm}^{3+}$ shown in column 5 agrees well with the predicted one. The conclusion at this stage is that there is a good agreement between the prediction from the VRBE schemes and the experimental data for $\mathrm{La}\left(\mathrm{PO}_{3}\right)_{3}: \mathrm{Ln}$.

For comparison we show the VRBE energy scheme for $\mathrm{LiYP}_{4} \mathrm{O}_{12}$ : $\mathrm{Ln}$ in Fig. 8. The values of $U(6, \mathrm{~A})$ for $\mathrm{La}\left(\mathrm{PO}_{3}\right)_{3}: \mathrm{Ln}$ and $\mathrm{LiYP}_{4} \mathrm{O}_{12}: \mathrm{Ln}$ are about the same. All 4f-related binding energies in Fig. 7 are then also at about the same absolute energies as in Fig. 8. The main difference between the two schemes is in the binding energy of the host bands and differences in the redshift that affect the absolute $5 \mathrm{~d}_{i}$-level locations. The valence band energy rises from $-9.99 \mathrm{eV}$ for $\mathrm{La}\left(\mathrm{PO}_{3}\right)_{3}$ to $-10.40 \mathrm{eV}$ for $\mathrm{LiYP}_{4} \mathrm{O}_{12}$; but the conduction band energy lowers from $-0.86 \mathrm{eV}$ to $-1.03 \mathrm{eV}$, respectively. The anion coordination around lanthanum in $\mathrm{La}\left(\mathrm{PO}_{3}\right)_{3}$ is eightfold in the form of a dodecahedron with point symmetry $\mathrm{C}_{2}$ like in $\mathrm{LiYP}_{4} \mathrm{O}_{12}$. The average La-O bond length is $253 \mathrm{pm}$ [24] which is longer than the $239 \mathrm{pm}$ in $\mathrm{LiYP}_{4} \mathrm{O}_{12}$.

The first VRBE scheme for $\mathrm{YPO}_{4}$ :Ln was presented in Ref. [16] and for other $\mathrm{REPO}_{4}: \mathrm{Ln}(\mathrm{RE}=\mathrm{La}, \mathrm{Gd}, \mathrm{Y}, \mathrm{Lu}, \mathrm{Sc})$ in Ref. [19]. In order to compare the level locations of the lanthanide states in different types of phosphate compounds the so-called stacked band structure diagram in Fig. 9 has been constructed. It compares the vacuum referred binding energy of the valence and conduction

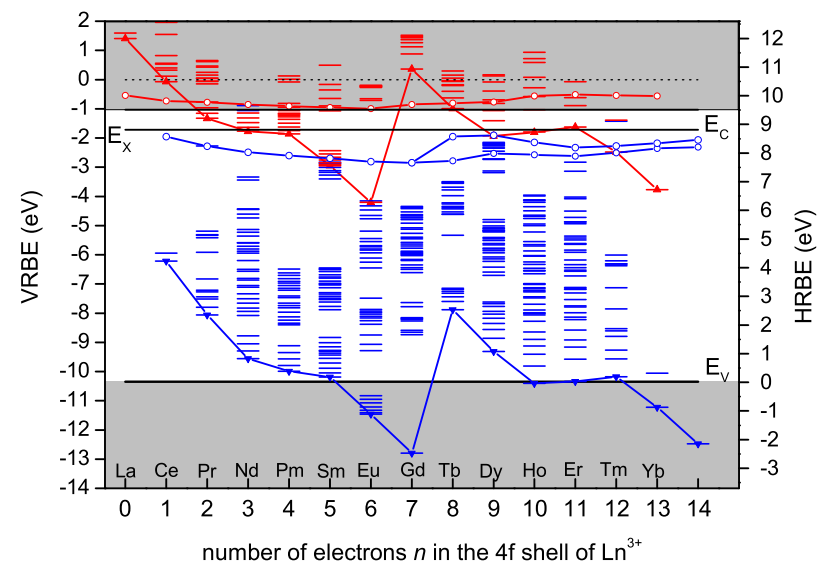

Fig. 8. The HRBE and VRBE scheme for the divalent and trivalent lanthanides in $\mathrm{LiYP}_{4} \mathrm{O}_{12}$.

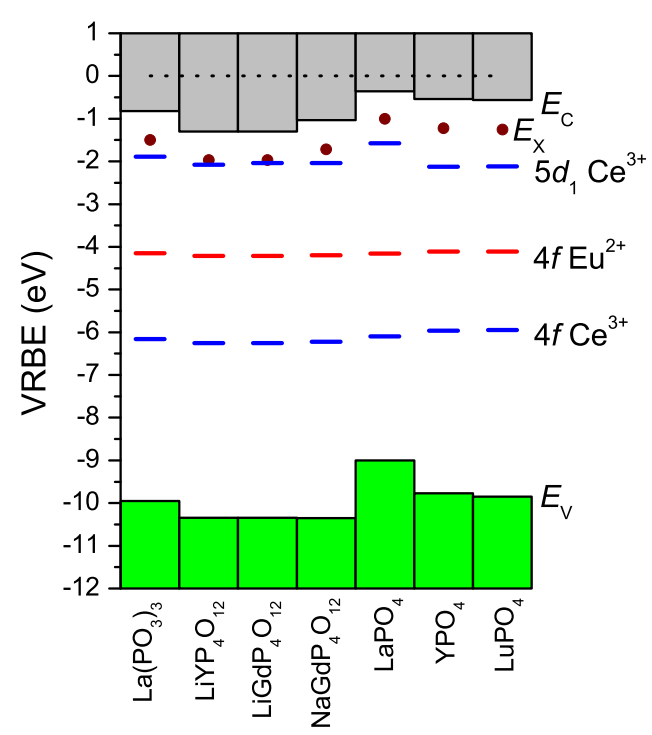

Fig. 9. Binding energy scheme showing the $\mathrm{Ce}^{3+}$ and $\mathrm{Eu}^{2+} 4 \mathrm{f}$ ground state levels and lowest energy $\mathrm{Ce}^{3+} 5 \mathrm{~d}_{1}$ together with the energy $E_{\mathrm{V}}$ at the top of the valence band and $E_{\mathrm{C}}$ at the bottom of the conduction band. The solid data symbol shows the binding energy $E_{\mathrm{X}}$ of the electron in the host exciton state.

bands of various phosphate compounds together with the ground state of $\mathrm{Ce}^{3+}$ and $\mathrm{Eu}^{2+}$, the first $5 d$-state of $\mathrm{Ce}^{3+}$ and the electron binding energy $E_{\mathrm{X}}$ in the exciton state $\left(E_{\mathrm{X}} \equiv E_{\mathrm{V}}+E^{\mathrm{ex}}\right)$. The data needed to construct the scheme are listed in Table 3.

The stacked scheme shows that the most important changes in the electronic scheme are due to changes in the valence band and the conduction band binding energy of the host compound. The impurity level ground state binding energies are fairly constant. Of particular interest for the temperature stability of the $5 d-4 f$ emission of $\mathrm{Ce}^{3+}$ is the energy difference $E_{\mathrm{dc}}$ between the $5 \mathrm{~d}_{1} \mathrm{Ce}$ level and the conduction and bottom. The values are listed in Table 3. Smallest $E_{\mathrm{dc}}$ is observed for $\mathrm{LaPO}_{4}$ where the lowest temperature stability of $\mathrm{Ce}^{3+} 5 \mathrm{~d}-4 \mathrm{f}$ emission is expected. $\mathrm{ALnP}_{4}$ $\mathrm{O}_{12}(\mathrm{~A}=\mathrm{Li}, \mathrm{Na})$ hosts will then provide better temperature stability due to an $E_{\mathrm{dc}}$ value above $1 \mathrm{eV}$ which is twice larger than for $\mathrm{LnPO}_{4}\left(\mathrm{Ln}=\mathrm{La}, \mathrm{Y}\right.$ and $\mathrm{Lu}$ ) orthophosphates. The studied $\mathrm{La}\left(\mathrm{PO}_{3}\right)_{3}$ host shows $E_{\mathrm{dC}}=0.86 \mathrm{eV}$ which is rather close to the $\mathrm{ALnP}_{4} \mathrm{O}_{12}$ hosts and which makes $\mathrm{Ln}$ doped $\mathrm{La}\left(\mathrm{PO}_{3}\right)_{3}$ compounds rather promising with respect to temperature stability of $\mathrm{Ce}^{3+} 5 \mathrm{~d}-4 \mathrm{f}$ emission. Furthermore, it has a single crystallographic site of Ln ions and relatively simple single phase synthesis. 
Table 3

Experimental data on the exciton creation energy $E^{\operatorname{ex}}(A)$ at the temperature near $10 \mathrm{~K}$ in the phosphate compounds and the results on $E_{\mathrm{V}}(\mathrm{A})$ and $E_{\mathrm{dc}}(\mathrm{A})$ from this work; all energies are in $\mathrm{eV}$.

\begin{tabular}{|c|c|c|c|c|}
\hline Compound & $E^{\mathrm{ex}}(\mathrm{A})$ & $E_{\mathrm{V}}(\mathrm{A})$ & $E_{\mathrm{dc}}(\mathrm{A})$ & Ref. \\
\hline $\mathrm{YPO}_{4}$ & 8.55 & -9.77 & -0.54 & [19] \\
\hline $\mathrm{LaPO}_{4}$ & 8.0 & -9.00 & -0.36 & [19] \\
\hline $\mathrm{LuPO}_{4}$ & 8.60 & -9.85 & -0.56 & [19] \\
\hline $\mathrm{La}\left(\mathrm{PO}_{3}\right)_{3}$ & 8.45 & -9.99 & -0.86 & This work \\
\hline $\mathrm{LiYP}_{4} \mathrm{O}_{12}$ & 8.63 & -10.4 & -1.03 & {$[22]$} \\
\hline $\mathrm{LiGdP}_{4} \mathrm{O}_{12}$ & 8.45 & -10.4 & -1.30 & [31] \\
\hline $\mathrm{NaGdP}_{4} \mathrm{O}_{12}$ & 8.30 & -10.3 & -1.30 & [31] \\
\hline
\end{tabular}

\section{Concluding remarks}

The luminescence spectroscopy of $\mathrm{Ce}^{3+}, \mathrm{Pr}^{3+}, \mathrm{Nd}^{3+}, \mathrm{Sm}^{3+}$, $\mathrm{Eu}^{3+}$ and $\mathrm{Tb}^{3+}$ in $\mathrm{La}\left(\mathrm{PO}_{3}\right)_{3}$ has been studied upon vacuum ultraviolet excitation at $T=10 \mathrm{~K}$. The vacuum referred binding energy scheme for all trivalent and all divalent lanthanides in $\mathrm{La}\left(\mathrm{PO}_{3}\right)_{3}$ has been constructed and the predictions energies of the $4 f-5 d$ transition of lanthanide ions agree with the experiment. The same applies for the predicted $C T$-band energies.

\section{Acknowledgments}

The work is supported by institutional research funding IUT (02-26) of the Estonian Ministry of Education and Research, Estonian Science Foundation Grant no 8678 and the 7th FP INCO.2010-6.1 Grant agreement no. 266531 (project acronym SUCCESS). T. Shalapska is grateful to the Marie Curie Actions Postdoctoral Research Grant no. 0057J.

The authors appreciate the support of HASYLAB (DESY, Hamburg) for the Superlumi experiments.

\section{References}

[1] S. Hachani, B. Moine, A. El-akrmi, M. Ferid, J. Lumin. 130 (2010) 1774.

[2] Yu Wang, D. Wang, J. Solid State Chem. 180 (2007) 3450.

[3] R. Ternane, M. Ferid, G. Panczer, M. Trabelsi-Ayadi, J. Phys. Chem. Solids 69 (2008) 1684.

[4] J.-L. Yuan, H. Zhang, J.-T. Zhao, H.-H. Chen, X.-X. Yang, G.-B. Zhang, Opt. Mater. 30 (2008) 1369.

[5] A. Jouini, J.C. Gâcon, M. Ferid, M. Trabelsi-Ayadi, Opt. Mater. 24 (2003) 175.

[6] A. Jouini, J.C. Gâcona, A. Brenier, M. Ferid, M. Trabelsi-Ayadi, J. Lumin. 99 (2002) 365.

[7] D. Wang, Y. Wang, Y. Shi, J. Lumin. 131 (2011) 1154.

[8] R. Ternanea, M. Ferid, G. Panczer, M. Trabelsi-Ayadi, G. Boulon, Opt. Mater. 27 (2005) 1832.

[9] H.S. Kiliaan, F.P. van Herwijnen, G. Blasse, J. Solid State Chem. 74 (1988) 39.

[10] M. Buijs, G. Blasse, J. Lumin. 39 (1988) 323.

[11] S. Hachani, B. Moine, A. El-akrmi, M. Ferid, J. Lumin. 130 (2010) 1774.

[12] H.A. Höppe, K. Kazmierczak, S. Kacprzak, I. Schellenberg, R. Pottgen, Dalton Trans. 40 (2011) 9971.

[13] D. Wang, Yu Wang, Y. Shi, J. Lumin. 131 (2011) 1154.

[14] P. Dorenbos, J. Lumin. 91 (2000) 155.

[15] P. Dorenbos, J. Lumin. 111 (2005) 89.

[16] P. Dorenbos, Phys. Rev. B 85 (2012) 165107.

[17] P. Dorenbos, ECS J. Solid State Sci. Technol. 2 (2013) R3001.

[18] P. Dorenbos, Phys. Rev. B 87 (2013) 035118.

[19] P. Dorenbos, J. Phys.: Condens. Matter 25 (2013) 225501.

[20] P. Dorenbos, J. Lumin. 134 (2013) 310.

[21] P. Dorenbos, J. Lumin 136 (2013) 122.

[22] P. Dorenbos, T. Shalapska, G. Stryganyuk, A. Gektin, A. Voloshinovskii, J. Lumin. 131 (2011) 633.

[23] G. Zimmerer, Radiat. Meas. 42 (2007) 859.

[24] P. Dorenbos, Phys. Rev. B 64 (2001) 125117.

[25] L. van Pieterson, M.F. Reid, R.T. Wegh, S. Soverna, A. Meijerink, Phys. Rev. B 65 (2002) 045113.

[26] A. Zych, M. de Lange, C. de Mello Donega, A. Meijerink, J. Appl. Phys. 112 (2012) 013536.

[27] T. Shalapska, G. Stryganyuk, D. Trots, Yu Romanuchun, A. Gektin, A. Voloshinovskii, P. Dorenbos, J. Phys. D: Appl. Phys. 43 (2010) 405404.

[28] A.M. Svirastava, A.A. Setlur, H.A. Comanzo, W.W. Beers, U. Happek, P. Schmidt, Opt. Mater. 33 (2011) 292.

[29] P. Dorenbos, J. Phys.: Condens. Matter 15 (2003) 6249.

[30] P. Dorenbos, J. Lumin. 135 (2013) 93.

[31] T. Shalapska, G. Stryganyuk, P. Demchenko, A. Voloshinovskii, P. Dorenbos, J. Phys.: Condens. Matter 21 (44) (2009) 445901. 